\title{
Effect of thermochemical treatments on the surface hardening of a circular saw blade: A microstructure comparison of nitride layers, boride layers and TiN coating formed on ASTM A1011 steel
}

Irving Morgado-González ${ }^{1}$, Martín Ortiz-Domínguez ${ }^{2}$, Oscar Gómez-Vargas ${ }^{3}$, Edgar Cardoso-Legorreta ${ }^{1}$, Jesús García-Serrano ${ }^{1}$, Mariana Bárcenas-Castañeda ${ }^{3}$, Víctor Castellanos-Escamilla ${ }^{3}$, Gina Moreno-González ${ }^{3}$ and José Solís-Romero ${ }^{3}$

${ }^{1}$ Universidad Autónoma del Estado de Hidalgo, Mineral de la Reforma, Hidalgo, Mexico, ${ }^{2}$ Universidad Autónoma del Estado de Hidalgo, Ciudad Sahagún, Hidalgo, Mexico, ${ }^{3}$ Instituto Tecnológico de Tlalnepantla, Estado de México, México, Mexico

Nowadays the primary goal of industries is to manufacture the product at a faster rate but at minimal cost and that too without sacrificing product quality. As long as conventional machining is utilized, in order to fulfill first requirement (faster production rate), the cutting speed and feed rate should have to be increased. However, this may lead to reduced circular saw blade life due to faster wear rate and higher heat generation. Hence, circular saw blade is required to change frequently, which will ultimately impose a loss for the industry as a result of idle time for changing tools. Cost of tool is also not negligible. A proposed solution consist of developing a hard, dense, wear- and corrosion-resistant coating formed on a surface with certain affinity in fracture toughness, as well as the creation of a dislocation interface that prevents the propagation of the corrosive medium to the substrate and the propagation of micro-cracks [1-12]. In particular, nitriding of tool surfaces is one of the most commonly used types of heat treatment of tool steels. The nitriding process increases the hardness of the surface layers as well as resistance to abrasion and corrosion. It has been shown by many researches that deep layers of up to $1.5 \mathrm{~mm}$ thickness, exhibiting a hardness ranging from 400 to $1100 \mathrm{HV}$, could be achieved by nitriding process. The nitrided layer resulting from this thermochemical process comprises two sublayers: an outer compound layer and an underlying diffusion zone (layer). The compound layer is often composed of $\varepsilon-\mathrm{Fe} 3 \mathrm{~N} 1+\mathrm{x}$ and $\gamma^{\prime}$-Fe4N nitrides [1]. Likewise, thermochemical boriding of iron alloys allows both single Fe2B and FeB-based polyphases coatings to be obtained and then used mainly to improve surface hardness (up to $2000 \mathrm{HV}$ ) and wear resistance of the components for tribological applications [2-6]. Finally, PVD (physical vapour deposition) is the one of the ways of their deposition onto tool steels substrate. Titanium nitride (TiN) has been used in the coating of tool steels since the mid-sixties. The reasons to coat cutting tools in a production situation are to increase tool life, to improve the surface quality of the product, and to increase the production rate. The advantages of TiN coating include high hardness (up to 2300 $\mathrm{HV}$ ) and adhesion, good ductility, excellent lubricity, high chemical stability and tough resistance to wear, corrosion and temperature [7-13]. In the present study, the microstructure of three coating configurations ( $\varepsilon-$ $\mathrm{Fe} 3 \mathrm{~N} 1+\mathrm{x} / \gamma^{\prime}-\mathrm{Fe} 4 \mathrm{~N}, \mathrm{Fe} 2 \mathrm{~B}$, and TiN) formed on an ASTM A1011 steel standard circular blade surface have been investigated at different temperatures by powder-pack nitriding, dehydrated paste-pack boriding and reactive PVD treatments. Powder-pack nitriding and dehydrated paste-pack boriding procedures were preferred in this study for its cost-effectiveness, and simplicity of the required equipment. The circular blade was embedded in a closed in a hexagonal case (AISI 316L stainless steel), as shown in Figure 1, using a powder mixture of calcium cyanamide $(\mathrm{CaCN} 2, \sim 24 \mathrm{wt} . \%$ of $\mathrm{N})$ and calcium silicate $(\mathrm{CaSi}, \sim 35 \mathrm{wt} . \%$ of the mixture) as an activator (see Figure 2). The nitriding temperature was carried out in a conventional furnace under a pure argon atmosphere at $853 \mathrm{~K}$ for $6 \mathrm{~h}$. The sample was sanded with $\mathrm{SiC}$ papers and the polished with $6-\mu \mathrm{m}$ diamond paste to a mirror finish. Likewise, the circular blade was also embedded in a closed in a hexagonal case (see Figure 1), having a dehydrated paste of boron powder mixture inside with an average particle size of $10 \mu \mathrm{m}$. Boriding mixture contains of B4C (active source of boron), Na3AlF6 (activator), SiC (inert filler), and $\mathrm{SiC} 8 \mathrm{H} 20 \mathrm{O} 4$ which is used to protect surfaces (see Figure 3). The powder-pack boriding process was carried out in a conventional furnace under a pure argon atmosphere at $1223 \mathrm{~K}$ for $6 \mathrm{~h}$ of exposure. The TiN coatings were obtained by using a target with high power impulse magnetron sputtering (HIPIMS) with $2000 \mathrm{~W}, 500$ $\mathrm{Hz}, 200 \mathrm{~ns}$ and three targets with direct current magnetron sputtering (DCMS) with $2500 \mathrm{~W}$ on each (see 
Figure 4). The sputtering targets were $\mathrm{Ti}$ ( > 99.8\%). Interlayers of pure Ti were deposited with $400 \mathrm{~V}$ biasvoltage on all substrates. TiN layers were deposited by using bias-voltages of $75 \mathrm{~V}$ and $150 \mathrm{~V}$. The TiN layers had thicknesses of approximately $1 \mu \mathrm{m}$ and $5 \mu \mathrm{m}$. The coatings were deposited at $723 \mathrm{~K}$ with a Nitrogen/Argon (99.97\% pure) atmosphere (Ar: N2 Ratio $=24: 5)$ and total pressure of $350 \mathrm{mPa}$ and $120 \mathrm{~min}$ of exposure time. The hard samples were ground with $\mathrm{SiC}$ abrasive paper up to grit 2500. The hard samples were grinded with $\mathrm{SiC}$ abrasive paper up to grit 2500 . Afterwards, the samples were polished using a diamond suspension with particle size of $6 \mu \mathrm{m}$, finishing with particle size of $3 \mu \mathrm{m}$. The depth of the surface coatings and morphology were analysed by SEM and EDS (JEOL JSM-6360 LV at $20 \mathrm{kV}$ ). The pin-on-disc tests were carried out in dry sliding conditions using a CSM tribometer. This machine is used to determine the magnitude of friction coefficient and wear as two surfaces rub together. Figure 5 shows the cross-sections and the EDS analysis obtained by SEM at the $\varepsilon-\mathrm{Fe} 3 \mathrm{~N} 1+\mathrm{x} / \gamma^{\prime}-\mathrm{Fe} 4 \mathrm{~N}$ (see Figure 5(a)), Fe2B (see Figure 5(b)), and TiN ((see Figure 5(c))) for the ASTM A1011 steel. These results demonstrate that the formed the $\varepsilon-\mathrm{Fe} 3 \mathrm{~N} 1+\mathrm{x} / \gamma^{\prime}-\mathrm{Fe} 4 \mathrm{~N}, \mathrm{Fe} 2 \mathrm{~B}$, and TiN top layers produced a hardness in the expected range, around 1100-2500 HV. Figure 5(d), (e) and (f) shows some areas undergoing a plastic deformation for the nitrided ASTM A1011 steel, borided ASTM A1011 steel and TiN coating respectively. The wear scar on surface of TiN coating is narrower compared to the nitriding and boriding processes (see Figure 5(f)) and a low friction coefficient. However, the thermochemical treatments show better adhesion to the substrate and proved to be effective in the production of high hardness and wear resistant layers.

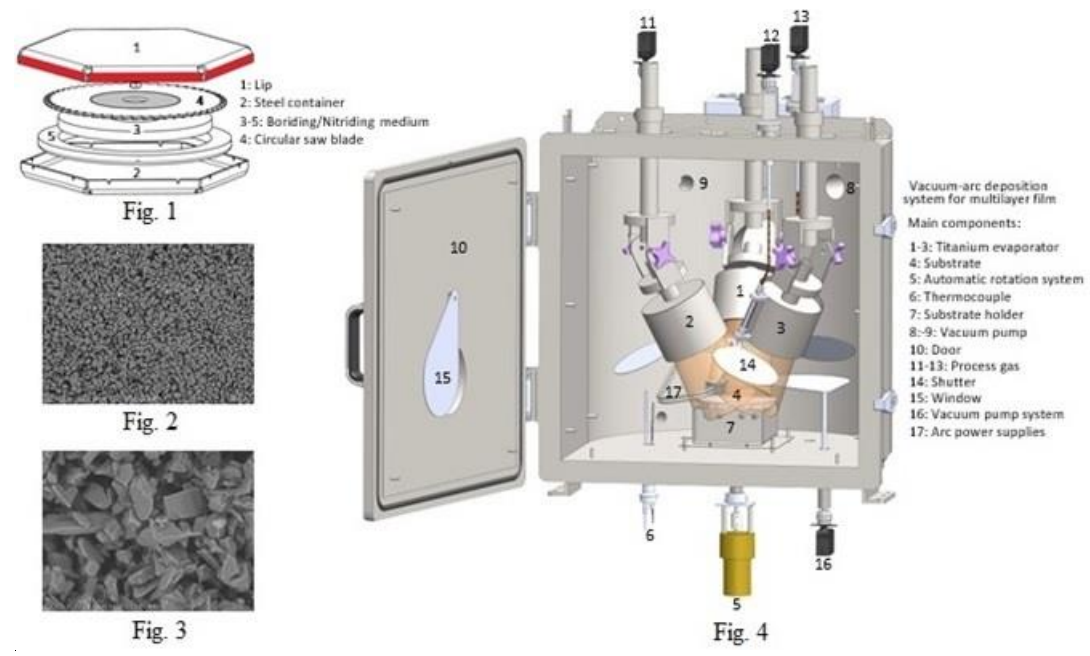

Figure 1. Figure 1. Schematic view of the stainless steel AISI 316L container for the powder-pack treatments, Powder nitriding medium (Figure 2), Powder boriding medium (Figure 3) and the schematic representation of the deposition reactor (Figure 4). 

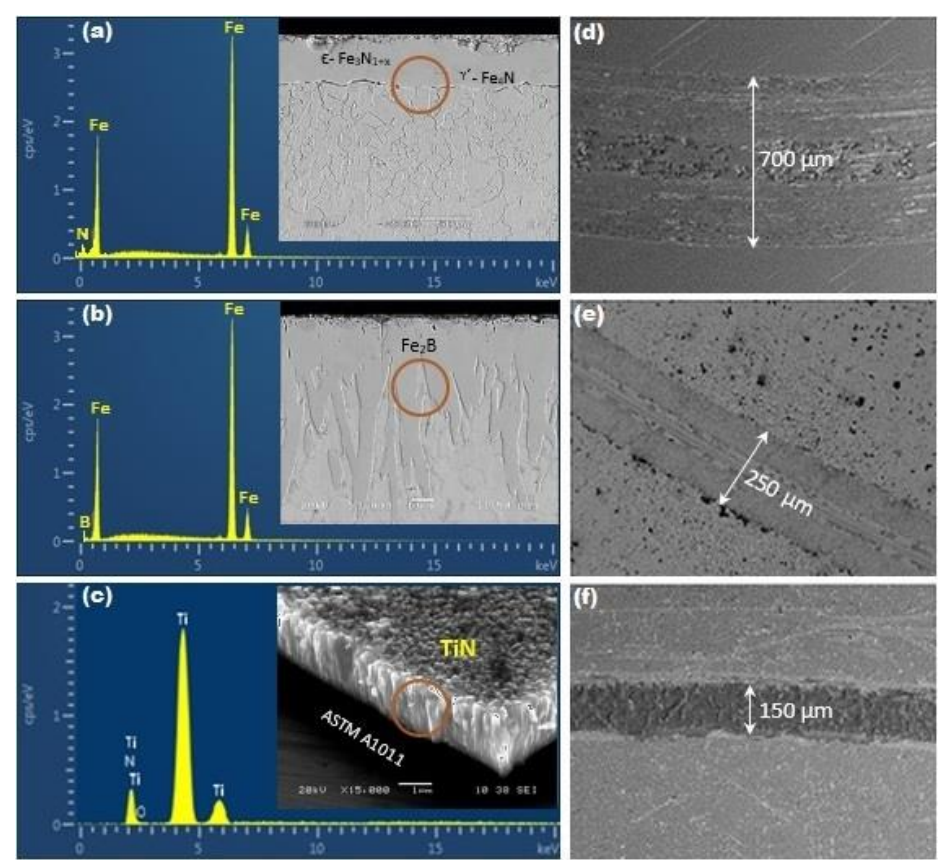

Figure 2. Figure 5. SEM cross-sectional micrograph and EDS analysis of: (a) nitrided ASTM A1011 steel with $853 \mathrm{~K}$ for $6 \mathrm{~h}$, (b) borided ASTM A1011 steel with $1223 \mathrm{~K}$ for $6 \mathrm{~h}$ and (c) TiN coating deposited on ASTM A1011 steel; and SEM (Figure 5) cross-sectional micrographs of the wear scar on surfaces of: (d) nitrided ASTM A1011 steel, (e) borided ASTM A1011 steel and (f) TiN coating.

\section{References}

[1] J. R. Davis. "Surface Hardening of Steels: Understanding the Basics", 1st ed. ASM, Ohio, p. 213.

[2] M. Ortiz-Domínguez, I. Morgado-González, A. Cruz-Avilés, A. Soto-García, R. Trujillo-Sánchez, M. L. Moreno-González, G. Moreno-González, O. A. Gómez-Vagas, J. Zuno-Silva, Microsc.Microanal. 25 (Suppl 2) 2019 , p. 2400.

[3] M. Ortiz-Domínguez, O. A. Gómez-Vargas, I. Simón-Marmolejo, M. A. Flores-Rentería, L. E. MartínezMartínez, A. Cruz-Avilés, M. A. Paredes-Rueda, Microsc. Microanal. 24 (Suppl 1) 2018, p. 1076.

[4] O. A. Gómez-Vagas, M. Ortiz-Domínguez, A. Cruz-Avilés, I. Morgado-González, J. Solis-Romero, V. A. Castellanos-Escamilla, E. Coronel-Guerra, E. Cardoso-Legorreta, Microsc. Microanal. 25 (Suppl 2) 2019, p. 770 .

[5] O. A. Gómez-Vargas, M. Ortiz-Domínguez, J. Solís-Romero, A. Arenas-Flores, I. Morgado González, J. Zuno-Silva, F. R. Barrientos-Hernández and J. Medina-Marín, Microsc. Microanal. 25 (Suppl 2) 2019, p. 796.

[6] M. Ortiz-Domínguez, O. A. Gómez-Vargas, G. Ares de Parga, G. Torres-Santiago, R. VelázquezMancilla, V. A. Castellanos-Escamilla, J. Mendoza-Camargo, and R. Trujillo-Sánchez, Advances in Materials Science and Engineering. 2019 (2019), p. 1.

[7] K. Y. Li and Z. D. Xiang, Surf. Coat. Technol. 204 (2010), p. 2268.

[8] Martín Ortiz-Domínguez, Ángel Morales-Robles, Oscar Gómez-Vargas and Jose Solis-Romero, Microsc. Microanal. 26 (Suppl 2) 2020, p. 2220.

[9] K. H. Habig, Mater. Eng. 2 (1980), p. 83.

[10] M. Flores, S. Muhl, L. Huerta, Surf. Coat. Technol. 200 (2005), p.1315.

[11] J. L. Bernal, E. Vera, A. I. Martínez, A. García, Microsc. Microanal. 24 (Suppl 1) 2018, p. 1102.

[12] Martín Ortiz-Domínguez, Oscar Gómez-Vargas, Jose Solis-Romero, Irving Morgado-González, Alberto Arenas-Flores and Jorge Zuno-Silva, Microsc. Microanal. 26 (Suppl 2) 2020, p. 2670.

[13] Oscar Gómez-Vargas, Martín Ortiz-Domínguez, Lizbeth Melo-Máximo, Dulce Melo-Máximo, Felipe Escalona-Cambray and Jose Solis-Romero, Microsc. Microanal. 26 (Suppl 2) 2020, p. 2216. 